Please do not remove this page

RMIT

UNIVERSITY

\title{
Child resilience: Relationships between stress, adaptation and family functioning
}

Mutimer, Annette; Reece, John; Matthews, Janet

https://researchrepository.rmit.edu.au/esploro/outputs/9921862948001341/filesAndLinks?institution=61RMIT_INST\&index=null

Mutimer, A., Reece, J., \& Matthews, J. (2007). Child resilience: Relationships between stress, adaptation and family functioning. Electronic Journal of Applied Psychology, 3(1), 16-25.

https://researchrepository.rmit.edu.au/discovery/fulldisplay/alma9921862948001341/61RMIT_INST:Resea rchRepository

Document Version: Published Version

Repository homepage: https://researchrepository.rmit.edu.au The content of this journal is licensed under $a<a$ rel='license' href='http://creativecommons.org/licenses/by-nc-nd/2.1/au/'>Creative Commons Attribution-NonCommercial-NoDerivs 2.1 Australia License</a> Downloaded On 2023/04/26 22:47:21 +1000 
Thank you for downloading this document from the RMIT Research Repository.

The RMIT Research Repository is an open access database showcasing the research outputs of RMIT University researchers.

RMIT Research Repository: http://researchbank.rmit.edu.au/

\section{Citation:}

Mutimer, A, Reece, J and Matthews, J 2007, 'Child resilience: Relationships between stress, adaptation and family functioning', Electronic Journal of Applied Psychology, vol. 3, no. 1, pp. 16-25.

\section{See this record in the RMIT Research Repository at:}

https://researchbank.rmit.edu.au/view/rmit:21762

Version: Published Version

\section{Copyright Statement:}

(C) The content of this journal is licensed under a Creative Commons Attribution-NonCommercial -NoDerivs 2.1 Australia License. http://creativecommons.org/licenses/by-nc-nd/2.1/au/

\section{Link to Published Version:}

http://pandora.nla.gov.au/pan/51365/20070816-0000/ojs.lib.swin.edu.au/index.php/ejap/article/view/7 6/104.html 


\title{
Child Resilience: Relationships between Stress, Adaptation and Family Functioning
}

\author{
Annette Mutimer (amutimer@parentingrc.org.au) \\ Parenting Research Centre \\ Carlton, VIC 3053 Australia \\ John Reece (john.reece@rmit..edu.au) \\ School of Health Sciences \\ RMIT University, Bundoora VIC 3083 Australia \\ Jan Matthews (jmatthews@parentingrc.org.au) \\ Parenting Research Centre \\ Carlton, VIC 3053 Australia
}

\begin{abstract}
The Resilience Classification Framework (RCF) was used to statistically identify four sub-groups $(n=74)$ from a larger sample of preschool aged children $(n=-$ 201). These four sub groups: Resilient ( $n=16)$; Good Expected $(n=20)$; Poor Expected $(n=24)$ and Vulnerable $(n=14)$ were compared across family functioning variables using the Family Assessment Device (FAD). Results showed that families experiencing high exposure to stress and adversity scored significantly lower on a range of family functioning variables than those reporting low exposure. Aspects of family functioning were found to be significantly different across the four sub groups. These were Problem Solving, Roles, Affective Involvement and General Family functioning.

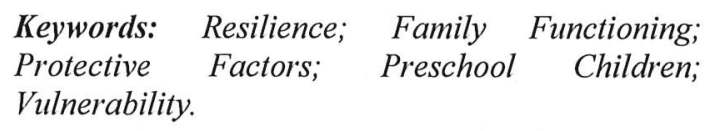

\section{Introduction}

Over the past decades, a growing number of researchers have focused on the effects of living in stressful, at-risk conditions on families and their children. Early research led to the significant discovery that exposure to risk and adversity did not necessarily result in negative outcomes (Rutter, 1987; Werner \& Smith, 1982). The term resilience has been used to describe these positive outcomes achieved by children in the face of adversity. Further, it can be defined as a child's capacity to overcome, adapt to, or minimize the damaging effects of adversity (Grotberg, 1995). This notion has led to a significant body of research examining the mechanisms that may protect children living in identified high risk situations. These mechanisms fall into three common protective areas: those relating to the child (child characteristics); those to the family (family structures and characteristics); and those relating to the wider community (environmental factors).

\section{Child Characteristics}

Child temperament has been found to be fundamental in whether children are classified as resilient or not resilient (Cowen, Wyman, Work, \& Parker, 1990; Engle, Castle, \& Menon, 1996; Werner \& Smith, 1982). Resilient children have been found to possess temperament characteristics in infancy that elicit positive responses from a wide range of caregivers. These children were described by their mothers as affectionate, easy to soothe and good-natured (Cowen et al, 1990). Other factors present in resilient children include an internal locus-of-control, a positive self concept, and good communication and social skills (Cowen et al., 1990; Engle et al., 1996; Tschann, Kaiser, Chesney, Alkon, \& Boyce, 1996).

\section{Family Characteristics}

In relation to family characteristics, the child/parent relationship has been found to be the most important factor for the development of resilience. To be considered resilient, a child needed a close bond with at least one caregiver (Cowen et al., 1990; Engle et al., 1996; Tschann et al., 1996; Werner \& Smith, 1982). Other important factors in the development of resilience include aspects of parenting such as the quality and continuity of care (Wyman et al., 1999), parenting confidence, and discipline practices (Cowen et al., 1990). Moos and Moos (1986) found resilient children came from families with lower levels of conflict and greater expressiveness in family relationships. Children in at-risk situations were also more likely to have resilient outcomes if they had not experienced prolonged separation from their primary caregiver, and had reasonable limits and consequences set in their 
home environment (Cowen et al., 1990; Grotberg, 1995).

Findings from additional studies suggest that socioeconomic variables, such as income and educational level of the parents differentiated between resilient and non-resilient children (Bradley et al., 1994; Cowen et al., 1990; Tschann et al., 1996). Further, that mothers of resilient children had significantly more education and higher levels of family income than mothers of nonresilient children. However, Werner (1995) and Grotberg (1995) found that protective factors and resilient outcomes transcended ethnic, social and geographic boundaries.

\section{Environmental Characteristics}

Families with a variety of external social supports appear to have children who are more resilient than those without such support (Block \& Block, 1980; Bradley et al., 1994; Cowen et al., 1990; Engle et al., 1996; Rak \& Patterson, 1996; Werner \& Smith, 1982; Wyman et al., 1999). Little information is available on the amount or quality of social supports, as purely the types of supports have been identified, including extended family, membership in a church or religious group, close friends, and participation in neighbourhood groups.

\section{Measuring Resilience}

Most research appears to rely on a common definition of resilience - the capacity to function in a normal range cognitively, socially and behaviourally in the face of adversity. A difficulty arises in developing an operational definition of resilience for the purpose of conducting research in the area. Problems arise in identifying the resilient child, classifying resilience amongst a population and setting criteria to judge resilience and non-resilience. This difficulty is twofold. The first issue relates to selecting appropriate underlying constructs theoretically relevant to resilience and, subsequently, reliable instruments to measure these. The second relates to how results from these instruments should be assessed in order to determine levels of resilience.

\section{Selecting Appropriate Constructs}

A review of literature identifies three main constructs relevant to positive developmental outcomes in young children: behavioural; social; and cognitive competence (Bradley et al., 1994; Kaufman, Cook, Arny, Jones, \& Pittinsky, 1994; Luthar, 1991; Tschann et al., 1996). In pre-school aged children, cognitive competence is perhaps the most difficult to determine. A distinction needs to be made between cognitive ability and academic competence. A measurement of cognitive ability may simply provide a reflection of genetic capabilities rather than a measure of the child's current level of achievement (Kinard, 1998).

Positive developmental outcomes in preschool aged children can then be defined in terms of behavioural and social competence. Competence can be defined as achievement of developmentally appropriate milestones or skills (Luthar, 1991). This suggests the presence of positive skills and development in addition to the absence of problem behaviours or negative developmental outcomes. In research, this translates to both the presence of positive adaptation as well the absence of negative adaptation. A child cannot be characterised as resilient with only one condition being met. For example: using the behavioural competence construct, there would need to be the presence of positive aspects of behaviour in young children e.g. initiative, in addition to the absence of negative behaviour problems such as aggression.

Family stress or stressful life events is an important construct in resilience research. Given that most definitions of resilience perceive the construct as a response to adversity, it would seem that without a measure of family stress or stressful life events, a study cannot purport to be measuring resilience, but instead be purely measuring child adaptation (Luthar, Cicchetti, \& Becker, 2000).

Many family and environmental characteristics have been identified in research as being related to resilience in young children. Luthar, Cicchetti and Becker (2000) suggest that research should now move beyond a simple measurement of family and environmental variables and examine mechanisms within families and how they contribute to resilience in children.

\section{Determining Resilience Status}

The Resilience Classification Framework (RCF), (Mutimer, Matthews \& Reece, 2006) provides a statistically sound method for resilience decision making. The RCF was developed to address the difficulties in assessing data to make resilience classifications. It enables the statistical identification of four sub groups: Resilient (high stress, good adaptation); Good Expected (low stress, good adaptation); Poor Expected (high stress, poor adaptation); and Vulnerable (low stress, poor adaptation) (Mutimer, Matthews \& Reece, 2006). The Adaptation construct consists of two components, one measuring the presence of the positive construct and the second measuring the absence of the negative construct. Raw data from these two constructs are examined using quartile splits. The top $25 \%$ and bottom $25 \%$ of both are labeled (High \& Low). To receive a classification of 'Good adaptation', participants must be labeled 'high positive' and 'low negative' (Mutimer, Matthews \& Reece, 2006). Exposure to stress is treated similarly. The top $25 \%$ and bottom $25 \%$ of scores are assigned 
labels of 'High' and 'Low'. Participants are then labeled based on a classification in both a stress condition and an adaptation condition (see Figure 1).

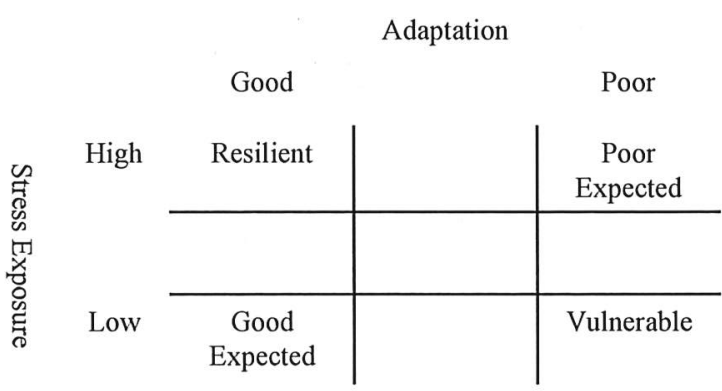

Figure 1: The Resilience Classification Framework

\section{Rationale and Aims of the Present Study}

The present study builds on the existing resilience research literature by examining the relationship of aspects of family functioning to resilience in young children. It is expected that the resilient group will show better quality family functioning than either group of poor adapters (Poor Expected and Vulnerable). The expected status of the Good Expected group in relation to the Resilient group is unclear from the literature and presents an additional research question to be explored in this study.

\section{Method}

Kindergartens from two local government areas within the Northern region of Melbourne $(N=42)$ were invited to assist in the distribution of study packages to parents of children attending their centres. Initially, a letter was sent to the teachers and to the committees of management for each pre-school briefly explaining the study. From this point, 11 kindergartens expressed interest and made contact.

A total of 500 questionnaire packages were distributed to parents at the 11 centres. A secure box was located at each centre to collect completed packages. One week after distribution, parents received a reminder notice. Then a further week later, a final notice was distributed specifying a date by which the box would be removed from the centre. One week from this date, the box was collected and a reply-paid envelope was left with the staff for any further responses.

\section{Materials and Procedure}

Child adaptation was assessed using the Social Skills Rating System (SSRS) (Gresham \& Elliot, 1990), and the Child Behaviour Check List (CBCL) (Achenbach, 1991). The CBCL is a well-known measure of child problem behaviour with well-established psychometric adequacy. It was used in this study to determine the presence or absence of child behaviour problems. It contains 108 items and uses a 3-point response format $(0=$ not true, $1=$ somewhat or sometimes true, $2=$ very true or often true). Two major subscale scores and a total problem behaviour score are derived. It is normed and standardised, providing clinical and non-clinical ranges in scores across many areas of behaviour problems (Achenbach, 1991).

Social competence was measured using the SSRS. This is a parent report measure of a child's social and interpersonal skills. The version used for this study is for children aged 3-5+ years. It consists of four subscales: Communication, Attention, Responsibility, and Self-Control. A total score is computed by summing the subscales. It is normed and standardised allowing scores to be converted to age-equivalents, or compared with same-aged peers (Gresham \& Elliot, 1990). The SSRS has been established as psychometrically sound (Gresham \& Elliot, 1990).

Aspects of family functioning were measured using the Family Assessment Device (FAD) (Epstein, Baldwin \& Bishop, 1982). The FAD is a 60 -item questionnaire, with a 4-point response scale (strongly agree, agree, disagree \& strongly disagree). The FAD contains seven inter-correlated subscales: Problem Solving, Communication, Roles, Affective Responsiveness, Affective Involvement, Behaviour Control and General Functioning. It is reported to have sound reliability and internal consistency with alphas ranging from .7 to .9 (Epstein, Baldwin \& Bishop, 1982).

Two instruments were used to provide a measure of family stress - the Daily Hassle Scale - Revised (DHSR), (Holm \& Holroyd, 1992), and the Life Experiences Survey (LES), (Sarason, Johnson \& Siegel, 1978). The DHS-R is 63-item self-report inventory designed to measure everyday sources of stress and annoyance over a one-month period. It provides a measure of occurrence and severity of stress and annoyance. The scale is reported to have good internal consistency, with an alpha of .80 (Holm \& Holroyd, 1992). The LES is designed to measure recent stressful life events, and also provides a measure of the parents' appraisal of the event. The LES is reported to have good construct validity and internal consistency, with an alpha of .78 (Sarason, Johnson \& Siegel, 1978).

Socio-demographic variables were obtained using questions relating to family structure, parental education levels, parental employment, gender and age of the child, birth order, and number of children in the family.

The primary caregiver was requested to complete the SSRS and the CBCL in relation to their kindergartenaged child, and complete the FAD, the DHS-R, the LES 
and the demographic information in relation to their family. Parents were asked to return completed questionnaires to the secure box at the kindergarten for collection.

\section{Results}

There were three phases to data analysis. First, the scores from the childhood behaviour and family stress measures were used to operationalise resilience and form four resilience-related groups. Second, Pearson correlations were performed to determine the relationships among the variables under investigation. Finally, aspects of family functioning were used as dependent variables, and were analysed in relation to the four resilience-related groups.

\section{Initial data screening and exploration}

All data were initially screened using exploratory data analyses to assess for normality, data entry errors, and notable distributions of results. None of the continuous variables exhibited a distribution of scores that precluded the use of parametric procedures.

A response rate of $40.2 \%$ was achieved $(N=201)$. Respondents were mainly mothers (96.5\%). Target children were between 37 and 72 months of age $(M=$ 57.6 months, SD $=7.38$ ). An almost even numbers of boys $(48 \%)$ and girls (52\%) were represented in the sample. The majority of children lived in two parent families (married \& de facto combined $-87.4 \%$ ), and $43.4 \%$ were the youngest child in the family. More than half came from two child families (54\%), with only $9.1 \%$ being only children.

Respondent parents had all completed some secondary schooling, with $17 \%$ having completed a diploma, $18 \%$ a degree, and $17 \%$ had gained a postgraduate qualification. A little over half were in part time employment (51\%), with $38.4 \%$ not working outside the home.

\section{Operationalising resilience}

Child adaptation was determined using the raw scores from the SSRS and the total T scores from the CBCL. As these measures provide scores in opposing directions with regard to positive adaptation, the total T scores on the CBCL were corrected using a reciprocal transformation, resulting in high scores reflecting an absence of problem behaviours. Scores from both measures were then transformed to z-scores and added to provide a single adaptation score for each participant. The decision to add the two scores rather than take their mean was based on the correlation between the SSRS and total $\mathrm{CBCL} \mathrm{T}$ score. Even though this correlation was significant, $r=.38, p<.001$, the corresponding $\mathrm{r}^{2}$ figure of $14.4 \%$ indicated that there was considerable unique variability being contributed by each measure.
Similarly, the raw impact score from the LES and the raw score from the DHS-R were also transformed to zscores, and added to provide a measure of exposure to stress and adversity. Percentile ranks were then examined for both the adaptation and exposure scores. The top $25 \%$ and bottom $25 \%$ of scores were then assigned the following labels: top $25 \%$ adaptation = good; bottom $25 \%=$ poor; top $25 \%$ exposure $=$ high; bottom $25 \%=$ low. Participants with high levels of stress and adversity and poor adaptation were identified and labelled 'Poor Expected'. Participants with high levels of stress and adversity and good adaptation were labelled 'Resilient'.

Participants with low levels of stress and adversity, and good adaptation were labelled 'Good Expected', and participants with low levels of stress and adversity and poor adaptation were labelled the 'Vulnerable' group.

In addition, participants whose results suggested adequate adaptation (e.g. $1 \mathrm{SD}$ above the mean) were included for analysis, using the classification system described above. This is based on the notion that a positive adaptation result for a child from a family experiencing very high levels of stress and adversity would be considered as a positive result. Robinson (2000) stresses that any analysis of resiliency should consider those participants with normal adaptation in the face of high stress as resilient, as well as those with excellent adaptation. Table 1 shows the outcomes of the classification; $36.8 \%$ of the total participant pool were classified into one of the four groups $(N=74)$.

Table 1 - 2 x 2 Cross-classification of Adaptation and Exposure

\begin{tabular}{ccccc}
\hline & & \multicolumn{3}{c}{ Adaptation } \\
\cline { 3 - 5 } & & Good & Poor & Total \\
\hline Exposure & High & 38 & 24 & 40 \\
& & (Resilient) & $\begin{array}{c}\text { (Poor } \\
\text { Expected) }\end{array}$ \\
& Low & 20 & 14 & 34 \\
& & $\begin{array}{c}14 \\
\text { (Good }\end{array}$ & (Vulnerable) & \\
& Total & 36 & 38 & 74 \\
\hline
\end{tabular}

\section{Analysis of exposure and adaptation groups on family functioning variables}

A $2 \times 2$ factorial multivariate analysis of variance (MANOVA) was conducted using the two factors of exposure to stress and adversity (high \& low) and adaptation (good \& poor) with the subscales from the FAD as the multiple dependent measures. The multivariate interaction was not significant, Wilks' $\Lambda=$ $.86, F(7,59)=1.40, \mathrm{p}=.22, \eta^{2}=.14$. A significant multivariate main effect for stress and adversity was 
found, Wilks' $\Lambda=.72, F(7,59)=3.28, \mathrm{p}=.005, \eta^{2}=$ .28. A significant multivariate main effect was also found for adaptation, Wilks' $\Lambda=.59, F(7,59)=6.12, p$ $<.001 \eta^{2}=.42$. For the stress and adversity main effect, significant univariate results were found for four of the seven dependent measures: Problem Solving, $F(1,65)=4.51, p=.038, \eta^{2}=.07$; Roles, $F(1,65)=$ $8.16, p=.006, \eta^{2}=.11$; Affective Involvement, $F(1$, $65)=19.93, p<.001, \eta^{2}=.24$; and General Functioning, $F(1,65)=7.49, p=.008, \eta^{2}=.10$.

Examination of the marginal means for the stress and adversity main effect showed that participants with low scores on exposure to stress and adversity scored higher on all four mentioned subscales (see Table 2).

Table 2 - Mean scores on family functioning subscales as a function of exposure level

\begin{tabular}{|c|c|c|c|}
\hline \multirow[t]{2}{*}{ Subscale } & & \multicolumn{2}{|c|}{ Exposure } \\
\hline & & High & Low \\
\hline Problem & $M$ & 15.04 & 16.06 \\
\hline Solving & $S D$ & .33 & .35 \\
\hline Communication & $M$ & 15.44 & 15.67 \\
\hline & $S D$ & .35 & .37 \\
\hline Roles & $M$ & 21.05 & 23.24 \\
\hline & $S D$ & .53 & .56 \\
\hline Affective & $M$ & 19.66 & 20.63 \\
\hline Responsiveness & $S D$ & .46 & .49 \\
\hline Affective & $M$ & 20.98 & 23.67 \\
\hline Involvement & $S D$ & .41 & .44 \\
\hline Behaviour & $M$ & 30.16 & 31.11 \\
\hline Control & $S D$ & .48 & .51 \\
\hline General & $M$ & 39.55 & 42.65 \\
\hline Functioning & $S D$ & .78 & .83 \\
\hline
\end{tabular}

For the adaptation main effect, significant univariate results were found of all seven dependent measures: Problem Solving, $F(1,65)=21.73, p<.001, \eta^{2}=.25$; Communication, $F(1,65)=12.27, p=.001, \eta^{2}=.16$; Roles, $F(1,65)=11.46, p=.001, \eta^{2}=.15$; Affective Responsiveness, $F(1,65)=10.20, p=.002, \eta^{2}=.14$; Affective Involvement, $F(1,65)=9.99, p=.002, \eta^{2}=$ .13; Behaviour Control, $F(1,65)=28.80, p<.001, \eta^{2}=$ .31 ; and General Functioning, $F(1,65)=18.67, p<$ $.001, \eta^{2}=.22$. Examination of the marginal means for the adaptation main effect showed that participants with good adaptation had higher scores on all subscales than those with poor adaptation (see Table 3 ).
Table 3 - Mean scores on family functioning subscales as a function of adaptation level

\begin{tabular}{cccc}
\hline Subscale & & \multicolumn{2}{c}{ Adaptation } \\
\cline { 3 - 4 } & & Good & Poor \\
\hline Problem & $M$ & 16.68 & 14.42 \\
Solving & $S D$ & .35 & .34 \\
Communication & $M$ & 16.45 & 14.67 \\
& $S D$ & .37 & .36 \\
Roles & $M$ & 23.44 & 20.85 \\
& $S D$ & .55 & .54 \\
Affective & $M$ & 21.22 & 19.08 \\
Responsiveness & $S D$ & .48 & .47 \\
& & & \\
Affective & $M$ & 23.28 & 21.37 \\
Involvement & $S D$ & .43 & .43 \\
Behaviour & $M$ & 32.49 & 28.77 \\
Control & $S D$ & .50 & .49 \\
General & $M$ & 43.54 & 38.65 \\
Functioning & $S D$ & .81 & .79 \\
& & & \\
\hline
\end{tabular}

\section{Comparison of groups on family functioning variables}

Given the lack of any meaningful interaction between exposure to stress and adversity and adaptation, a further single-factor MANOVA was conducted, using the four group classifications as a single betweensubjects factor. This was to facilitate a more detailed analysis of the four groups.

A single-factor between-subjects MANOVA was conducted with the seven subscales scores of the FAD as the dependent measure found a significant multivariate effect, Wilks' $\Lambda=.44, F(21,183)=2.88$, $p<.001, \eta^{2}=.24$.

Significant univariate results were found for groups on all seven subscales: Problem Solving, $F(3,65)=$ 10.43, $p<.001, \eta^{2}=.33$; Communication, $F(3,65)=$ 4.64, $p=.005, \eta^{2}=.18$; Roles, $F(3,65)=7.75, p<$ $.001, \eta^{2}=.26$; Affective Responsiveness, $F(3,65)=$ $4.69, p=.005, \eta^{2}=.18$; Affective Involvement, $F(3$, $65)=11.83, p<.001, \eta^{2}=.35$; Behaviour Control, $F(3$, $65)=12.3, p<.001, \eta^{2}=.36$; and General Functioning, $F(3,65)=10.19, p<.001, \eta^{2}=.32$.

Subsequent post-hoc testing using Tukey's HSD on the seven significant univariate test results revealed several patterns of significance amongst groups for some FAD subscales. No significant result was found for the Resilient group results when compared to the other three groups on subscales except for general 
family functioning. However, the Good Expected group (low exposure \& good adaptation) showed significantly higher scores when compared to the poor adapting groups (Poor Expected and Vulnerable) The Good Expected group were significantly different to the Vulnerable group (low exposure \& poor adaptation) and to the Poor Expected group (high exposure \& poor adaptation) on the Problem Solving (see Figure 2), Communication (see Figure 3), and Behaviour Control subscales (see Figure 4).

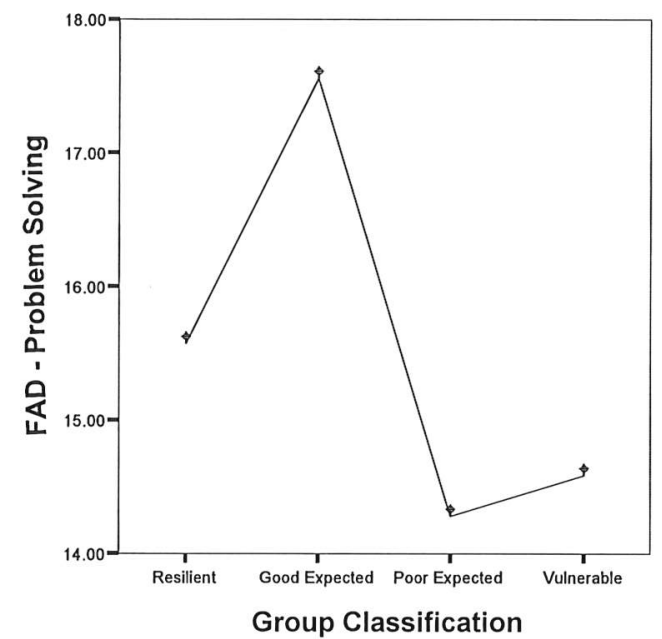

Figure 2: Mean score on Problem Solving subscale for the four identified groups

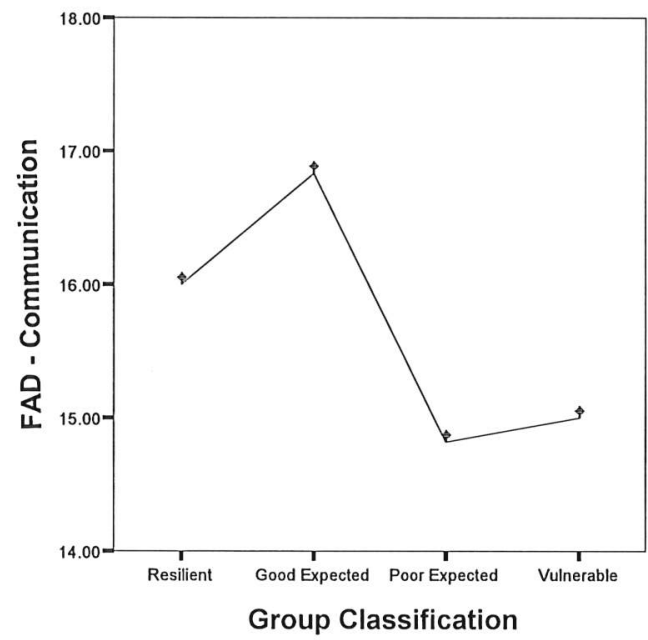

Figure 3 - Mean score on Communication subscale for the four identified groups

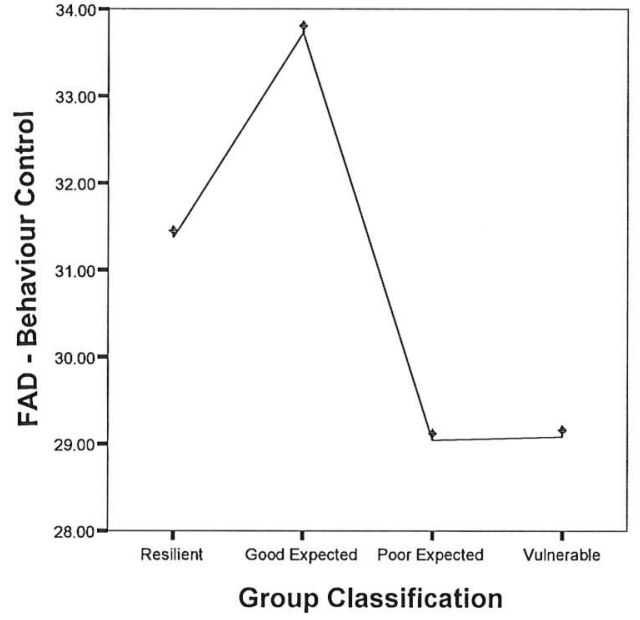

Figure 4: Mean score on Behaviour Control subscale for the four identified groups

Groups behaved similarly on the general functioning subscale with the Good Expected group having significantly higher scores than the Vulnerable and the Poor Expected groups. Interestingly, a significant difference was found between the Poor Expected group and the Resilient group, with the Resilient group having significantly higher scores that the Poor Expected group (see Figure 5).

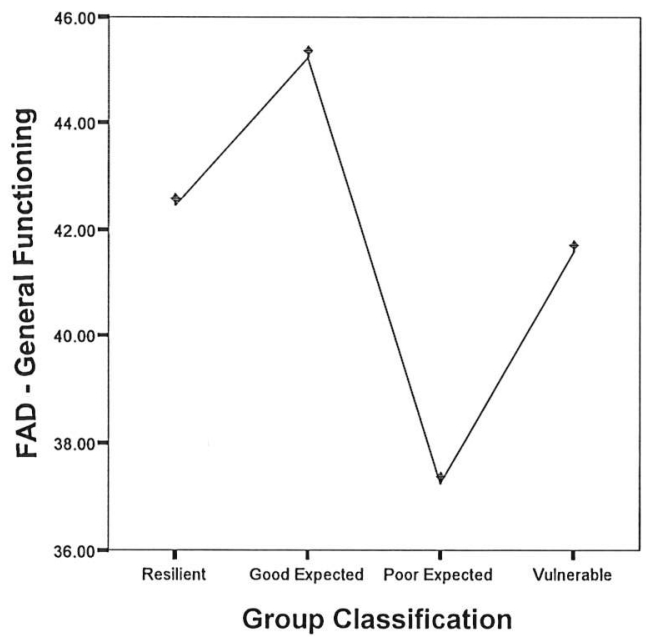

Figure 5: Mean score on General Functioning subscale for the four identified groups

Another notable pattern emerged with two other subscales: Roles and Affective Responsiveness. The Good Expected group had significantly higher scores on 
these two subscales than the Poor Expected group (see Figure 6).
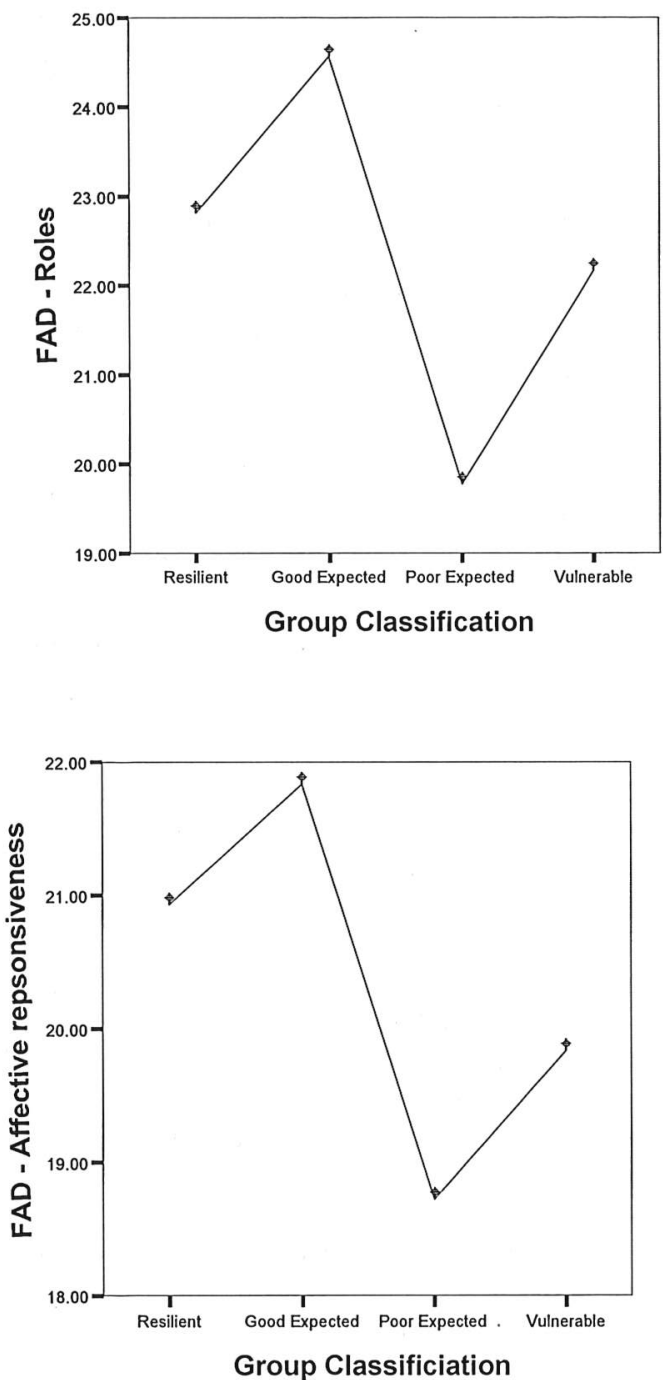

Figure 6: Mean scores on Roles \& Affective Responsiveness subscales for the four identified groups

The only subscale not to conform to either pattern was Affective Involvement. On this subscale, the Good Expected group scored significantly higher than either the Resilient or Poor Expected groups. In addition, a significant difference was found between the Poor Expected and the Vulnerable groups, with the latter having higher Affective Involvement scores (see Figure 7).

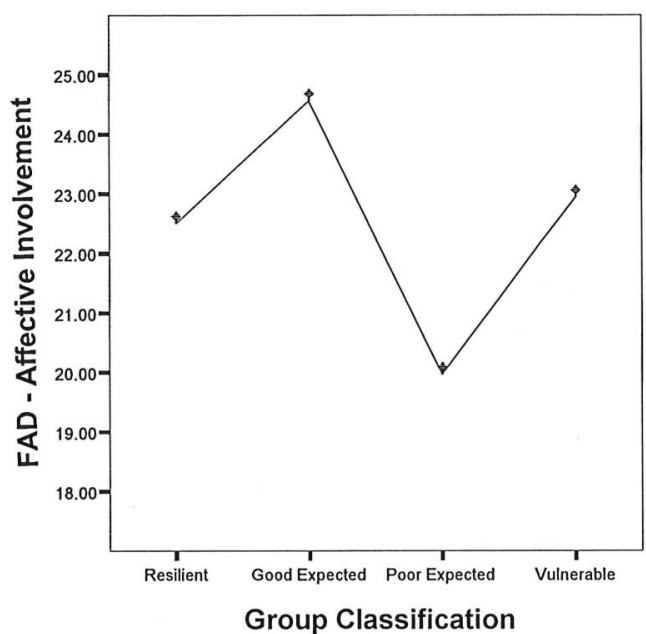

Figure 7: Mean scores on Affective Involvement subscale for the four classified groups

\section{Discussion}

The main results to emerge from this study can be summarised as follows: exposure to stress and adversity and adaptation were found to be statistically independent of each other when examined with family functioning variables. However, further analysis revealed a significant main effect for both exposure level and adaptation on family functioning. In general, participants exposed to higher levels of stress, had lower scores on family functioning variables than those with lower exposure levels. Conversely, participants with positive adaptation scored more highly on all family functioning variables than those with poor adaptation. Further, the four classified groups: Good Expected, Poor Expected, Vulnerable and Resilient were compared across all seven subscales of the FAD. Interestingly, the Resilient group scored higher on all family functioning variables except for affective involvement. However this difference only reached significance for the Resilient group when compared to the Poor Expected group on general family functioning. In addition, the Resilient group did not differ significantly from the Good Expected group on any aspect of family functioning with the exception of affective involvement. With the exception of this scale the resilient group appeared to have experienced family functioning that may well have provided a buffer against poor outcomes.

In examining specific subscales, the Good Expected group scored significantly higher than Poor Expected group. Additionally, they had significantly greater scores than the Vulnerable group on Problem Solving, 
Communication, Behaviour Control and General Functioning. Other results of note related to the Resilient group, who scored significantly higher on General functioning that the Poor Expected group, and had significantly lower scores on Affective Involvement in comparison with the Good Expected group.

The results reported above make several noteworthy contributions to the resilience literature. Most previous research on resilience has focused on adaptation to stress and adversity in older children under particular conditions of adversity (e.g. divorce, poverty). In the present study, children came from a 'typical' range of families experiencing varying levels of stress. Other studies have also focused on protective factors within the child, family or environment as predictors of resilience, whilst this study examined mechanisms within the family itself. Two other aspects of this study are particularly notable. One is the development of a methodological framework that was used successfully to operationalise resilience quantitatively on the basis of scores derived from well-established measures of stress, adversity, behaviour and social skills. This framework not only provided a method for reliably operationalising resilience, it also produced three other interesting groups of participants. Of particular interest is the Vulnerable group. This group is experiencing relatively poor adaptation in the light of very low exposure to stress and adversity. This group presents as clearly atrisk and warrants further investigation. As far as can be established, this is the first time that resilience has been operationalised in this way, particularly with young children. The examination of the impact of family mechanisms provided interesting results. In general, families reporting high exposure to stress and adversity scored lower on a range of family functioning aspects, than those reporting low stress. Those aspects of family functioning that were found to be significantly different across stress conditions were Problem Solving, Roles, Affective Involvement and General Family functioning.

Interestingly, those aspects differentiated between families with high and low exposure, whereas others such as Communication, Affective Responsiveness and Behaviour Control did not.

While no causal relationship can be established, it is interesting to speculate on whether different aspects of family functioning have different relationships to stress. It may be that the level of stress within the family affects family members' ability to resolve difficult situations (Problem Solving) and/or the range of appropriate emotions to a range of situations (Affective Responsiveness). Conversely, an inability to carry out assigned tasks, proving support and managing family systems (Roles) may add to the level of stress experienced by the family.
A similar relationship was found between child adaptation and these family mechanisms. Children with good adaptation (good social and communication skills $\&$ an absence of problem behaviours) came from families who reported better family functioning across all areas. It is interesting to speculate whether good family functioning facilitates good adaptation or whether the reverse is true. Certainly, literature is available to support either hypothesis. Sanders (1995) describes the detrimental effects of child problem behaviour on family mechanisms. Other literature supports a more 'environmental' perspective of the family environment affecting a child's adaptation.

Closer inspection of the four groups identified in this study reveal an interesting pattern of results. The Good Expected group (low exposure, good adaptation) reported significantly better family functioning in some areas, than either the Vulnerable group (low exposure, poor adaptation), or the Poor Expected group (high exposure, poor adaptation). As the resilient group was not found to differ significantly from the Good Expected group, it may be suggested that these aspects of family functioning act protectively against poor outcomes in the face of stress.

Interestingly no significant difference was found between the Resilient group and either Vulnerable or the Poor Expected groups, except for General Functioning. Aside from this aspect, other aspects of family functioning can best be described as 'protectivereactive' to adaptation and exposure (Luthar, Cicchetti $\&$ Becker, 2000). Protective-reactive relates to a pattern where the mechanism provides advantages, but less so when stress levels are high rather than low (Luthar, Cicchetti \& Becker, 2000). This can be best illustrated with an example - the Problem Solving subscale (see Figure 2). Little apparent difference is observed on Problem solving between 'resilient' children and Vulnerable group. However, the Good Expected group has a higher mean score than any other group. It appears that once exposure to stress increases, the effect of this positive mechanism lessens.

The relationship between Affective Involvement as a dimension of family functioning and the four participant groups bears closer examination. This subscale appears to differentiate well between groups. Affective Involvement is described as the extent to which family members are interested and involved in things that are important to other members. A higher score relates to an 'intermediate' level of involvement, neither too little nor too much (Epstein, Baldwin \& Bishop, 1983, p.173). It may be that this aspect acts as a protective mechanism in resilience or this finding may be age specific to pre-school aged children. Previous research has noted that differing aspects of family environments were relevant to resilience definition at different ages (Bradley et al, 1994; Tschann et al, 1996; 
Wyman et al, 1999). The level of affective involvement of parents with their children, not over or under involved, may provide a valuable clue to understanding resilience promotion in young children.

Further, the overall subscale of General Functioning produced several interesting results. This aspect provided the best differentiation between groups. General Functioning assesses overall healthy functioning and family pathology (Epstein, Baldwin \& Bishop, 1983). In this study, almost every group differed significantly from others on this measure. It may be that this subscale alone provides the best measure of difference between the four identified groups, in the pre-school age group. Both of these aspects should be explored further in future research to determine the nature of these family mechanisms across children of different ages and developmental stages.

\section{Limitations and conclusions}

Findings of this study were limited to a particular age group (children 4 to 6 years) and the socio-demographic combination of the sample, which may not have been a genuine cross-section of the target population. This sample could be described as predominately two-parent families and thus findings may have limited external validity. Additionally there was no method of gathering information from the individuals who chose not to respond to the questionnaire, to determine how they differed from the participant group, and as such no way of determining if the sample was representative of the population. Further no attempt was made to observe or assess the children independently; measures obtained were reliant on parent report for both adaptation and exposure levels.

Of note was the percentage of children classified as resilient, $7.96 \%(n=16)$. This figure is a function of the method of defining resilience and must be viewed in the context of this sample. These children were identified as resilient in comparison to their sample peers and should be considered as such. Within a different sample, these children may or may not be considered resilient. It would be essential to look at the robustness of these results through a follow up study with a larger sample.

In summary, this study has provided a useful framework for operationalising resilience with young children. From a clinical perspective, this framework will be useful in identifying at-risk children and families for intervention. Further, it has provided some insight into mechanisms within families that act as protective agents in resilience.

\section{References}

Achenbach, T., M. (1991). Child Behavior Checklist for Ages 4-18. Burlington: University of Vermont.
Block, J. H., \& Block, J. (1980). The role of ego-control and ego-resiliency in the organisation of behavior. In W. A. Collins (Ed.), Development of cognition, affect and social relations. The Minnesota Symposia on Child Psychology. NJ:Erlbaun: Hillsdale.

Bradley, R. H., Whiteside, L., Mundfrom, D. J., Casey, P. H., Kelleher, K. J., \& Pope, S. K. (1994). Early indicators of resilience and their relation to experiences in the home environments of low birth weight, premature children living in poverty. Child Development, 65, 346-360.

Cowen, E. L., Wyman, P. A., Work, W. C., \& Parker, G. R. (1990). The Rochester Child Resilience project: overview and summary of first year findings. Development and Psychopathology, 2, 193-212.

Engle, P. L., Castle, S., \& Menon, P. (1996). Child development: Vulnerability and resilience. Social Science and Medicine, 43, 621-635.

Epstein, N. B., Baldwin, L. M., \& Bishop, D. S. (1983). Family Assessment Device, Version 3. Journal of Marital Therapy, 9, 117-180.

Gresham, F. M., \& Elliott, S. N. (1990). Social Skills Rating System Manual and test booklets. Minnesota: American Guidance Service.

Grotberg, E. (1995). A guide to promoting resilience in children strengthening the human spirit. Hague: The Bernard Van Leer Foundation.

Holm, J. E., \& Holroyd, K. A. (1992). The Daily Hassles scale (revised): Does it measure stress or symptoms? Behavioral Assessment, 14, 465-482.

Kaufman, J., Cook, A., Arny, L., Jones, B., \& Pittinsky, T. (1994). Problems defining resiliency: Illustrations from the study of maltreated children. Development and Psychopathology, 6, 215-229.

Kinard, E. M. (1998). Methodological issues in assessing resilience in maltreated children. Child Abuse \& Neglect, 22, 669-680.

Luthar, S. (1991). Vulnerability and resilience: A study of high-risk adolescents. Child Development, 62, 600-616.

Luthar, S. S., Cicchetti, D., \& Becker, B. (2000). Research on Resilience: response to commentaries. Child Development, 71(3), 573-575.

Moos, R. H. \& Moos, B. S. (1986). Family Environment Scale Manual. Palo Alto, CA: Consulting Psychologists Press.

Mutimer, A., Matthews, J \& Reece, J. (2006). Family functioning and its relationship to child resilience in preschool children. In M. Katsikitis (Ed.), Joint Conference of the APS and NZPSS: Bridging the Tasman, Science, Culture and Practise. Melbourne: Australian Psychological Society.

Rak, C. F., \& Patterson, L. E. (1996). Promoting resilience in at-risk children. Journal of Counseling \& Development, 74, 368-373. 
Robinson, J. L. (2000). Are there implications for prevention research from studies of resilience? Child development, 71, 570-572.

Rutter, M. (1987). Psychosocial resilience and protective mechanisms. American Orthopsychiatric Association, 57, 316-331.

Sanders, M. R. (1995). Families and mental health. In M. R. Sanders (Ed.) Healthy families: Healthy nation (pp. 9-33). Brisbane: Australian Academic Press.

Sarason, I. G., Johnson, J. H., \& Siegel, J. M. (1978). Assessing the impact of life changes: Development of the Life Experiences Survey. Journal of Consulting and Clinical Psychology, 46(3), 932-946.

Tschann, J. M., Kaiser, P., Chesney, M. A., Alkon, A., \& Boyce, W. T. (1996). Resilience and vulnerability among preschool children: family functioning, temperament, and behavior problems. Journal of American Academy of Child and Adolescent Psychiatry, 35, 184-192.

Werner, E. E. (1995). Resilience in development. Current Directions in Psychological Science, 4, 8185

Werner, E. E., \& Smith, R. S. (1982). Vulnerable but invincible: A longitudinal study of resilient children and youth. New York: McGraw-Hill.

Wyman, P. A., Cowen, E. L., Work, W. C., HoytMeyers, L., Magnus, K. B., \& Fagen, D. B. (1999). Caregiving and developmental factors differentiating young at-risk children showing resilient versus stressaffected outcomes: A replication and extension. Child development, 70, 645-659.

Correspondence to: Annette Mutimer

Parenting Research Centre

24 Drummond Street, Carlton, VIC 3053

amutimer@parentingrc.org,au

\section{Research Profile}

Annette Mutimer is a PhD scholar at the Parenting Research Centre. Her research forms part of the work in the parenting for strength and resilience stream in the research and practice division of the centre. Annette's current research builds on previous work in the preschool resilience area to look at specific aspects of parenting practices and their relationship to resilience in young children.

John Reece is a senior lecturer in the Division of Psychology, School of Health Sciences at RMIT University. His research interests fall into four main areas: positive psychology, particularly resilience; university teaching and learning; research methods; and children's psychosocial wellbeing, particularly in the context of school bullying. Over the last few years,
John has been working with several higher degree students on the development and application of a psychometrically sound method for operationalising resilience and applying it to a range of populations, including bully victims, Aboriginal adolescents, preschool students and young adults. John has also been consulted extensively on research reports and grant applications for his expertise in the area of research methods and data analysis.

Jan Matthews is currently Director of Research and Practice at the Parenting Research Centre.

Jan has been involved in the tertiary education sector for over thirty years as a lecturer, senior lecturer and currently as Associate Professor. Before joining the Centre, she was Program Leader for Post Graduate Psychology programs at RMIT University.

Jan's interests include program development and research on parenting and family inventions, staff training and program evaluation. She has been a manager/principal investigator for a number of research and government grants including projects to develop and trial Signposts for Building Better Behaviour and the national Healthy Start initiative. Jan is also principal author of five program manuals for parents and professional, including the Signposts materials 